\title{
Articles
}

\section{Implications of Egalitarianism and Religiosity on Relationship Satisfaction}

\author{
Brittni J. Glenwright* ${ }^{\star a}$, Darren M. Fowler \\ [a] University of Toronto, Toronto, Canada. [b] Department of Psychology, Saint Mary's University, Halifax, Canada.
}

\begin{abstract}
Egalitarianism has been demonstrated to be an important component of relationship success and satisfaction. Moreover, studies have shown religiosity to be an influential factor on gender role attitudes. The present research attempts to clarify the association between religiosity and relationship satisfaction as mediated by egalitarianism, by correcting for some limitations of previous studies similar in focus. To minimize confounding variables that exist when assessing married couples on relationship satisfaction (such as possible financial barriers and stigma of divorce), the sample primarily consisted of unmarried students, who were assessed using two distinct measures of relationship satisfaction. Additionally, a multidimensional assessment of religiosity was employed, including intrinsic, extrinsic and quest as well as church attendance. Results showed a positive association between relationship satisfaction and egalitarianism, and a negative association between egalitarianism and various measures of religiosity. A weak negative correlation was found between religiosity and relationship satisfaction. Limitations and directions for future research are discussed.
\end{abstract}

Keywords: egalitarianism, religiosity, relationship satisfaction

Interpersona, 2013, Vol. 7(2), 215-226, doi:10.5964/ijpr.v7i2.137

Received: 2013-08-12. Accepted: 2013-11-07. Published (VoR): 2013-12-20.

${ }^{*}$ Corresponding author at: 191 St. George Street, Suite \#210, Toronto, ON, M5R 2M6. E-mail: britt_glenwright@hotmail.com

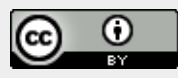

This is an open access article distributed under the terms of the Creative Commons Attribution License

(http://creativecommons.org/licenses/by/3.0), which permits unrestricted use, distribution, and reproduction in any medium, provided the original work is properly cited.

While happiness within a romantic relationship is dependent on numerous variables, much research has shown a positive link between egalitarianism and relationship satisfaction (e.g. Rudman \& Phelan, 2007). Furthermore, studies have verified religiosity to be an influential factor on women's gender role attitudes (e.g. Sherkat, 2000). While there is an abundance of literature on the association between religiosity and relationship satisfaction, results have been highly inconsistent. Given that to date, no research has incorporated these three variables into one comprehensive study, the present investigation seeks to clarify the links between them: exploring egalitarianism as a possible mediating factor.

\section{Religiosity and Relationship Satisfaction}

Religiosity can be defined as the quality of being religious; having or showing belief in, and reverence for, a God or deity (Merriam-Webster's Collegiate Dictionary, 1993). Results of investigations regarding the influence of religiosity on relationship and marital satisfaction vary considerably, however the discrepancies may be at least partially accounted for by differences in measurement. One study by Fincham, Beach, Lambert, Stillman, and Braithwaite (2008) found a positive correlation between religiosity and relationship satisfaction. Young couples that regularly engaged in religious prayer (either by themselves or together) reported high levels of happiness and satisfaction in their relationships. Prayer was regarded as a contribution to their love, respect and commitment. 
The authors point out, however, that the act of praying may not be the most objective method to assess the association between the two variables, given that praying as a couple may contribute to overall relationship satisfaction in so much as numerous other joint activities would.

In contrast to the aforementioned research, a study by Curtis and Ellison (2002) compared conflict within religious couples of similar and dissimilar religious backgrounds, and found that religious couples (with identical or different religious backgrounds) have a higher incidence of conflict, contributing to lower relationship satisfaction. Conflict was found to have arisen primarily from monetary issues and discrepancies between gender roles, such as the belief that women are required to do the majority of domestic labor.

Sullivan (2001) found that while religiosity was not related to marital satisfaction, it did predict more conservative attitudes toward divorce, increased commitment, and increased likelihood of seeking help in times of marital distress. These findings are supported by prior research that found a reciprocal, yet weak relationship between religion and marital quality. Booth, Johnson, Branaman, and Sica (1995) found that marital satisfaction was merely correlated with church attendance and religious influence in everyday life, supporting the previous assertion that religiosity is not related to marriage satisfaction. Several other studies have simply shown a lack of correlation between religiosity and relationship satisfaction (Orathinkal \& Vansteenwegen, 2006; Sussman \& Alexander, 1999; Wallin, 1957; Zehrung, 1998).

Some research has shown that religious couples are more likely to enjoy happy and stable marriages, less likely to experience conflict and violence, and less likely to divorce (e.g. Bahr \& Chadwick, 1985; Ellison, Bartkowski, \& Anderson, 1999; Kunz \& Albrecht, 1977). These findings, however, could be due to the method of measuring religiosity, as many studies have done so by simply inquiring about the frequency of church attendance (e.g. Kunz \& Albrecht, 1977; Wilson \& Musick, 1996). Although highly religious people likely go to church more often than those who are less religious, church may also be regarded as a shared social activity, and thus may not be fully representative of scope of one's religiosity per se. Moreover, some Abrahamic religious denominations argue for the "indissoluble marriage", encouraging efforts to keep families intact regardless of circumstances, thus presenting the couple with a barrier to divorce (Bahr \& Chadwick, 1985). This is another potential methodological drawback of some aforementioned studies in that relationship satisfaction was not measured inherently; rather, it was measured by evaluating divorce rates (e.g., Bahr \& Chadwick, 1985).

An intriguing study by Hansen (1987) showed that religious wives remained satisfied in their relationships regardless of recognizing little reward. These results could be interpreted as being due to religiosity compensating for couples vulnerabilities; thus maintaining satisfaction despite them. Conversely, it could be due to socially desirable responding (Sullivan, 2001). Dudley and Kosinski (1990) found marital satisfaction to be linked with correspondence between spouses with regards to church attendance and spirituality, but not religiosity itself. The researchers suggest that the perceived relationship between marital satisfaction and religiosity is likely merely the sharing of worship activities.

\section{Egalitarianism and Relationship Satisfaction}

Egalitarianism may be defined as "affirming or promoting, or characterized by belief in equal political, economic, social, and civil rights for all people" (Merriam-Webster's Collegiate Dictionary, 1993). Egalitarianism within a romantic relationship has been linked with greater relationship satisfaction for both men and women (Gerson, 1993). 
Over the past several decades, as women's education, employment, income, and status have risen, so has their overall share of decision making, leading to more egalitarian, less patriarchal relationships (Spain \& Bianchi, 1996). More so than ever, wives are contributing substantially to the workforce, and they are less often leaving it during childrearing years. Much research on the implications of these changes has emerged in order to determine if this decline in traditional values has created happier, or more hostile marriages (Spain \& Bianchi, 1996).

Equity, which denotes the subjective sense of fairness and overall appraisal of the proportion one gives and takes from a relationship, has been linked to marital happiness for both husbands and wives (Bagarozzi \& Wodwarsky, 1977). The vast majority of individuals ( $90 \%$ of women and $87 \%$ of men) agree that in relationships both partners should have "exactly equal say" regarding decision making (Thornton \& Young-DeMarco, 2001).

Gerson (1993) reported that husbands who endorse egalitarian attitudes spend more time doing housework and childcare. In a longitudinal study, Amato and Booth (1995) found that over time, increases in egalitarianism were associated with decreases in problems, disagreements, and likelihood of divorce in married couples. When housework is shared between husbands and wives, both tend to be happy, however, when there exists an imbalance in how work is divided, regardless of gender, the one doing more work tends to be unhappy (Amato, Booth, Johnson, \& Rogers, 2007). Women who are in relationships with egalitarian men report greater happiness, health, more stability, and greater sexual satisfaction than those in relationships with men who endorse traditional gender roles (Rudman \& Phelan, 2007). Knudson-Martin \& Mahoney (2009) emphasize that as equality sets the groundwork for open communication and mutual influence, relationship success is promoted for both of the sexes. Non-traditional gender role attitudes have been linked with improvements across multiple dimensions of marital quality (Amato, Johnson, Booth, \& Rogers, 2003).

In partial contradiction to these findings, Rabin and Shapira-Berman (1997) found that while women perceive less marital tension and greater satisfaction when role division and decision-making are equally shared, men did not. While recognizing the inequality, men perceived themselves as having a fair deal when they held the upper hand, and rated their marriages as more equitable than did their wives. Consistent with these findings, Amato, Johnson, Booth, and Rogers (2007) also found that marital quality decreased for men, but increased for women, when husbands upped their share of housework.

One essential measure of gender equality is work force participation (Hoffmann \& Miller, 1997). Although society's acceptance of women's participation in the workforce has increased, their expected level of housework has not decreased, as it remains on average 4.1 more hours per week than men (Ellison \& Bartkowski, 2002). As asserted by Hochschild and Machung (1989), household division of labor can be seen as a foundation in the structure of contemporary gender inequality. In addition, domesticity and reliance on male counterparts for primary labor contributions is encouraged, while attainment of higher education and career orientation is discouraged (Ellison \& Bartkowski, 2002).

The theme of inequality between women and men appears to hold true in unmarried youth as well. Armitage and Dugan (2006) investigated youth based religious groups, finding that they incorporated gendered language, traditional gender roles, and explicit behavioral expectations and restrictions for males and females. Males, who held the majority of power positions within the ministry, predominantly expressed leadership and authority. Conversely, females, who generally held lower positions in the ministry, showed expressions of submissiveness and obedience. 


\section{Egalitarianism and Religiosity}

A wealth of literature has revealed the influence of religiosity on women's gender role attitudes (Bartkowski, 1999; Lehrer, 1995; Sherkat, 2000). Read (2003) showed that women who participate in and belong to religious denominations tend to be more traditional in their gender role orientations, thus less egalitarian than those devoid of religious affiliation. Findings by Rose (2001) verified that many Christian churches advocate traditional patriarchal familial structures, justified under the assumption that by divinity, men and women were designed as fundamentally different.

In the Islamic faith, patriarchy, as well as norms that regulate familial roles, marriage, and divorce, is regarded as manifestations of God's will. Socially and legally, women are defined as subordinate to men. Huntington, Fronk, and Chadwick (2001), found that $73 \%$ of Muslim wives reported that they did most or all of the housekeeping and childrearing, while their husbands were the primary breadwinners.

\section{Rationale}

As many of the reviewed investigations have been executed with potentially insufficient methods, the present study will attempt to clarify the associations between egalitarianism, religiosity, and relationship satisfaction by correcting for some of these limitations. This study is also unique in that as of yet, no research has examined atheists as an individual group. Thus, the present research will focus on Christians, Muslims, agnostics, and atheists.

Many of the studies that showed a positive correlation between religiosity and relationship satisfaction demonstrated this by assessing divorce rates. Research by Johnson (1999) has argued people maintain relationships for personal, structural, and moral reasons. Moral commitment refers to that which exists because one feels they ought to continue the relationship despite their satisfaction level, as it would be improper to break their promises or vows. It may be most influential for religious individuals who feel that breaking a marriage vow to their spouse would also be breaking a vow to God, as often stated in the marriage ceremony. As a result, unmarried couples may provide a better sample to study the underlying connection between religiosity and relationship satisfaction.

The fact that the present research will focus on unmarried couples is novel, and should control for possible confounding factors related to relationship satisfaction scores, such as the stigma of divorce, structural barriers, and financial barriers. As some previous research has measured religiosity on a one-dimensional level, such as church attendance (e.g., Kunz \& Albrecht, 1977; Wallin, 1957; Wilson \& Musick, 1996), the current research employs a multidimensional assessment of religiosity, including intrinsic, extrinsic, and quest, as well as church attendance, and the degree to which respondents endorse the belief system presented in the scripture of their faith.

\section{Hypotheses}

Hypothesis 1: On the measure of egalitarianism, highly religious individuals will score lower (indicating the endorsement of more traditional sex role attitudes), and those who identify as less religious will score higher (indicating the endorsement of more liberal and egalitarian attitudes).

Hypothesis 2: Christians and Muslims who follow "holy scripture" will score lower on the measure of egalitarianism than those who do not. Specifically, those who interpret scripture literally will report a less egalitarian attitude than those who interpret it metaphorically. 
Hypothesis 3: Egalitarianism will be positively associated with relationship satisfaction.

Hypothesis 4: Regarding reports of relationship satisfaction, there will be no difference between atheists and Abrahamic religious groups.

\section{Method}

\section{Participants}

One hundred seventy nine undergraduate psychology students studying at an Eastern Canadian university (142 female, and 37 male) between the ages of 18 and 40 (mean age $=21.36$ ) completed the study. Participants, all of whom identified as heterosexual, reported to be single (38.3\%), in a casual relationship or dating (25\%), in a relationship $(43.4 \%)$, or married $(3.9 \%)$. Those in the latter three groups were then combined into a single "in a relationship" group (61.7\%) for easy comparison to those not currently in a relationship. Participants who were "in a relationship" at the time of the study reported the length of their relationship thus far as: zero to three months (17.1\%), three to six months $(12.6 \%)$, six months to one year $(17.1 \%)$, one to three years $(33.3 \%)$, or over three years $(19.8 \%)$.

\section{Procedure}

A compiled booklet of surveys, including measures of religiosity, egalitarianism, relationship satisfaction, and a demographic questionnaire were administered to the participants. No overt recruitment was involved; the study was simply posted on the sona-system website for students wishing to obtain extra credit for classes (two bonus points were awarded to students who participated in the study). The administration and completion of the survey took between 20 and 35 minutes. Prior to completion, all participants were informed that their participation was completely voluntary and that they could withdraw from the study at any time. All read and signed an informed consent form and were given a debriefing form afterwards to notify them of the purpose of the study, as well as contact information for any further questions or concerns. The demographic questionnaires and booklets were coded to be matched; however no personal identifying information could be discerned from any of the questionnaires, as consent forms remained separate.

\section{Measures}

Demographic Questionnaire - Participants filled out a basic demographic survey, asking for their age, country of origin, country they were raised and details about their relationships.

Religiosity - In order to obtain basic categories of participants' religiosity, the Dawkins Theist / Atheist Scale (DTAS) was administered. The DTAS (Dawkins, 2006) is a one-item measure that allows a person to rank the strength of his or her religious beliefs on a scale of one (strong theist) to seven (strong atheist). Participants identified as: "strong theist" (I do not question the existence of God, I know he exists); "de-facto theist" (I cannot know for certain but I strongly believe in God and I live my life on the assumption that he is there); "weak theist" (I am very uncertain, but I am inclined to believe in God); "pure agnostic" (God's existence and non-existence are exactly equiprobable); "weak atheist" (I do not know whether God exists but I'm inclined to be skeptical); "de-facto atheist" (I cannot know for certain but I think God is very improbable and I live my life under the assumption that he is not there); or "strong atheist" (I am 100\% sure that there is no God). 
In addition to the DTAS to measure religiosity, the Religious Life Inventory (RLI; Batson, Schoenrade, \& Ventis, 1993) was adapted for applicability to Muslims and agnostics, as well as all Christian faiths. The 9-point likert-type scale encompasses several domains of religiosity including interest in religion, attendance to place of worship, intrinsic (25 items), extrinsic (20 items), and quest (12 items) religiosity, as well as doctrinal orthodoxy (6 items). The present scale measures these different ways of being religious separately, as extrinsic religiosity is that which is used as a means to some end; intrinsic, religion is seen as an end in itself; and quest, religion is utilized as a quest for answers. The doctrinal orthodoxy section is intended to measure the extent to which an individual believes in traditional religious doctrines, for example, "I believe God created the universe" (Batson et al., 1993). Some items were removed from this section as they were exclusively Christian oriented, thus inappropriate for the purposes of this research (e.g., "I believe Jesus Christ is the Messiah promised in the Old Testament"). The items pertaining to each separate construct were distributed throughout the questionnaire, rather than in separate sections, and seven un-scored buffer items were included. To control for acquiescence, several items utilized reversed scoring. This multidimensional measure should provide a more accurate assessment of religious beliefs as it covers a wide array of dimensions and perspectives. The reliability and validity of the RLI have been assessed in more than 50 studies, and are outlined in the test creators' book Religion and the Individual (Batson et al., 1993). Batson et al.'s (1993) study comprised of undergraduate students verified the reliability of the RLI to be adequate, obtaining the following coefficients for each scale: internal $(\alpha=.84)$, external $(\alpha=.79)$, and quest $(\alpha=.78)$. Another study of undergraduate students by McMillen, Helm, and McBride (2011) generated comparable measures of reliability for the internal $(\alpha=.84)$, external $(\alpha=.70)$, and quest $(\alpha=.72)$ scales, respectively.

Although all participants completed the booklet in its entirety, scores on the RLI for participants identified as atheist (indicating between a five and seven on the DTAS) were not used, as the items were not applicable, and thus not valid or discriminating ("strongly disagree" was indicated for all questions).

Egalitarianism and Sex Role Attitudes - The 25-item version of the Attitudes Toward Women Scale (AWS; Spence \& Helmreich, 1972) was used to measure egalitarianism and sex role attitudes. The scale covers a wide range of attitudes regarding vocational, educational, and intellectual roles, freedom and independence of women, equality, dating etiquette, drinking, use of language, and relationship obligations and roles. The mechanism of response is from 0 (agree strongly) to 3 (disagree strongly), with the low score (minimum 0) indicating endorsement of traditional sex roles, and high score (maximum 75) indicating a liberal, egalitarian perspective. The AWS was selected over others of its kind due to its comprehensiveness and demonstrated psychometric properties. Having been used in hundreds of studies since the 1980's, the AWS is one of the most popular scales of egalitarianism to date (Beere, 1990).

Relationship Satisfaction — Relationship satisfaction was assessed using two separate measures: the Relationship Assessment Scale (RAS; Hendrick, Dicke, \& Hendrick,1998), and the Quality of Marriage Index (QMI; Norton, 1983). Both scales were chosen for their brevity and all encompassing nature, as well as their applicability to a wide range of participants, whether dating, cohabiting, engaged, or married. The RAS employs a 7-item, 5-point likert-type scale, measuring several facets of satisfaction in intimate relationships. It also inquires about love for the partner, problems in the relationship and how the relationship compares to most. The RAS has been verified to have high test-retest reliability $(r=.85)$ and internal consistency $(\alpha=.86)$, as well as construct, convergent, and predictive validity (Hendrick, Dicke, \& Hendrick, 1998). 
While the RAS assesses general relationship satisfaction, the QMI taps into the quality: the degree to which it is good, strong, stable, and happy. Responses are given on a scale from 1 (very strongly disagree) to 7 (very strongly agree), with the exception of the final item assessing happiness of the relationship, which ranges from 1 (unhappy) to 10 (perfectly happy). This was done in order to provide a larger range of response options, however was given equal weight to other items, and scaled down accordingly. The QMI has also demonstrated good psychometric properties over several studies (Heyman, Sayers, \& Bellack, 1994).

\section{Results}

\section{Hypothesis 1}

Regarding Hypothesis 1, correlations were run to determine the relationship between egalitarianism and religiosity. Due to the small sample obtained from followers of Judaism, they were omitted from the study. The following results refer to a sample comprised of Christians, Muslims, agnostics, and atheists. Using 2-tailed Pearson correlations, egalitarianism was shown to be significantly and negatively correlated with extrinsic religiosity $(r=-.312$, $p<.01)$, intrinsic religiosity $(r=-.271, p<.01)$, and doctrinal orthodoxy $(r=-.273, p<.01)$. Regarding doctrinal orthodoxy and intrinsic religiosity, significant correlations were also found on beliefs such that the father should have greater authority than the mother regarding bringing up children $(r=-.197 ; p<.05)$, and that women should not be sexually intimate with anyone before marriage $(r=-.627, p<.01)$. Significant negative relationships were additionally found between egalitarianism and interest in religion $(r=-.277, p<.01)$ and frequency of participation in religious ceremony $(r=-.351, p<.01)$.

With regards to the DTAS, due to the relatively small sample size of each group, three new groups were formed: theist (comprised of strong, de-facto, and weak theists, $51.7 \%$ ), agnostic (11.7\%), and atheist (comprised of strong, de-facto, and weak atheists, $36.6 \%$ ). Of those in the theist group, $47.2 \%$ identified as Christian, and $5 \%$ as Muslim. Atheism, as measured by the DTAS, was positively correlated with egalitarianism $(r=.225, p<.01)$. A one-way analysis of variance indicated significant mean differences in egalitarianism between groups on the DTAS $(p<$ .0001). Pair wise comparisons using Tukey's HSD showed significant differences as well, the largest being between strong theists and de-facto atheists $(p<.05)$.

\section{Hypothesis 2}

Hypothesis 2 was concerned with the relationship between egalitarianism and the following of holy scripture. An analysis of variance demonstrated significant mean differences in egalitarianism between groups regarding reading and interpretation of religious scripture $(p<.006)$ with the largest difference, as indicated by Tukeys HSD, between those who interpret scripture literally (least egalitarian), and those who do not read scripture at all (most egalitarian). Significant mean differences in egalitarianism between religious affiliations (Christian, Muslim, agnostic, and atheist) were also demonstrated, with $p<.0001$. The most egalitarian were atheists $(\mu=65.13)$, followed by agnostics $(\mu=64.45)$, Christians $(\mu=62.20)$, and lastly, Muslims $(\mu=45.89)$ who reported the least egalitarian attitudes.

\section{Hypothesis 3}

Hypothesis 3 was regarding the association between egalitarian attitudes and relationship satisfaction, proposing a potential positive relationship between the two. Egalitarianism was significantly correlated with relationship satisfaction on the RAS $(r=.224, p<.05)$, however not with the QMI $(r=.127)$. Scores between the QMI and RAS correlated as $r=.751(p<.01)$. In order to control for inaccurate and negative responses of participants reflecting 
back to previous relationships, only those currently in a relationship were used to assess any correlations between relationship satisfaction and other variables $(n=110)$.

\section{Hypothesis 4}

With respect to Hypothesis 4, correlations were run to determine the link between relationship satisfaction and religiosity. Using the RAS and QMI scores, no significant relationships were found between relationship satisfaction and religiosity, however there were weak negative correlations for frequency of participation in religious ceremony (QMI $r=-.140$; RAS $r=-.131$ ), extrinsic religiosity (QMI $r=-.080$; RAS $r=-.053$ ), intrinsic religiosity (QMI $r=$ .125; RAS $r=-.044$ ) and doctrinal orthodoxy (QMI $r=-.200$; RAS $r=-.196)$. The RAS also produced a significant positive correlation with atheism $(r=.201, p<.05)$. The mean RAS scores differed between affiliations with Muslims having the lowest mean score $(\mu=3.29)$, then Christians $(\mu=4.01)$, agnostics $(\mu=4.04)$ and atheists $(\mu=4.26)$, however were not significant. Using the DTAS, mean RAS scores were lowest for "strong theists" $(\mu=3.75)$ and increased progressively to the highest scores for "strong atheists" $(\mu=4.51)$.

\section{Discussion}

\section{Hypothesis 1}

Consistent with Hypothesis 1 and previous research on the topic, egalitarianism was negatively associated with various measures of religiosity. Frequent participation in religious ceremony (e.g., attending church or mosque) and literal interpretation of scripture was associated with more traditional gender role attitudes. Significant correlations were also found between religiosity and the endorsement of specific items on the measure of egalitarianism, such that women should be regarded as less capable of contributing to economic production than are men, and that they should be more concerned with duties of childbearing and house tending, rather than desire professional or occupational advancement.

\section{Hypothesis 2}

Consistent with Hypothesis 2, those who acknowledged a literal interpretation of Holy Scripture were less egalitarian $(\mu$ score $=2.30$ ) than those who interpreted it as metaphorical $(\mu=2.44)$, or did not follow any holy scripture at all $(\mu=2.57)$.

\section{Hypothesis 3}

As predicted and in accordance with previous research, the present sample showed support for Hypothesis 3, with egalitarianism being positively correlated with relationship satisfaction. Although the relationship itself is not novel, the nature of it may be. While most previous studies concerning these factors examined married couples only, the present study focused mainly on those in dating relationships, thus egalitarianism as a predictor means much more than the sharing of housework.

\section{Hypothesis 4}

In support of Hypothesis 4, regarding relationship satisfaction, no significant difference was found between atheists and religious individuals. It can be seen in the data that those who were religious reported to be slightly less satisfied in their relationships, although not significantly. From the results of this study, as has been the case with previous research, it is still unclear whether a true relationship between these variables exists. 


\section{Limitations}

The insignificant strength of the correlation between religiosity and relationship satisfaction could be valid in that only a weak, negative relationship exists in the population. Conversely, a true negative relationship may exist; the sample size of the present study may simply be too small to yield significant results for these variables. Indeed, the diverse nature of the various affiliations posed a problem, which was dealt with by placing various related affiliations in the same category. For example, as there were not enough Protestant, Roman Catholic, Eastern Orthodox, or Methodist individuals to arrange in individual categories, they were grouped into one. Although they are all Christian denominations, there are fundamental differences between them. Another issue that arose was that several individuals reported themselves to be Christian, but concurrently atheist as well. This raises the question of how much they endorse beliefs associated with Christianity. Some may have reported to be "Christian" because they were raised in a Christian family, however they may not personally internalize or identify with the teachings or values of Christianity. In order to control for this, attendance to religious ceremony was assessed. The usefulness of knowing the frequency of such attendance is limited however, as some may attend ceremony frequently but not endorse the attitudes and values brought forth. Conversely, others may never attend ceremony, yet deeply internalize the teachings and attitudes taught by their parents, or learned some time in the past. As there are so many different religious affiliations and interpretations, and all individuals internalize their faith to different degrees, religiosity proves to be a difficult construct to accurately measure. The multidimensional nature of the scale used in the present study was surely more accurate than other one-dimensional measures of the same construct; however, in depth interviews of each individual may be needed to properly assess religiosity.

The limited demographic of this study may pose a problem of external validity, in that it was comprised of solely Canadian, psychology undergraduate students, showing an interest in their academic achievement by participating for bonus points. The relatively small sample size did pose a problem in obtaining a sufficient number of Jewish and Muslim participants in order to have an adequate and equal sample of all three Abrahamic religious groups. There may also be an influence of a gender bias as the female participants greatly outnumber the male participants.

Another limitation of this research was the relationship status of several participants. Upon analysis of scores on the RAS and QMI, those who were reflecting back to their last relationship appeared to do so with a negative bias and had to be left out of some parts of the study to only include those currently in relationships. In addition, although measures of relationship satisfaction were chosen to accommodate more casual relationships (e.g., 0-3 months), it is probable that the egalitarianism of those and their partners in very new relationships is less important at that stage than various other factors. A bias towards social performance and partner acceptability within these new relationships may play a factor here. Finally, although the QMI is a very general measure of relationship satisfaction, and the questions it poses are not specific to marital relationships particularly, the fact that the measure was intended for married couples poses an additional limitation to the study.

\section{Future Research}

It would be beneficial in future research to organize a study in which both partners of a couple could be assessed. In such a case, satisfaction, egalitarianism, and religiosity of both partners could be compared. The congruence between their attitudes may explain the various relationships more so than the attitudes themselves. Religious affiliation of the participant's family of upbringing may also be important regarding internalization of values and attitudes, than the current belief system of the individual. Egalitarianism may also be looked at in this respect, as 
this belief is also internalized as an attitude or value early on. It may also be beneficial for future research to encompass couples of a variety of ages, as opposed to the limited demography utilized within this study. Having a larger selection of religions within the sample may as well provide a less biased result.

The results of the present study have contributed to existing knowledge of the interactions between egalitarianism and religiosity, as well as that of relationship satisfaction and egalitarianism. Utilization of a young, mostly unmarried population of couples has presented a unique view on these variables. Results suggest that there may be some type of correlational relationship between egalitarianism and religious views affecting relationship satisfaction. Further research is required to clarify how religiosity affects relationship satisfaction, and the extent to which other factors influence this association.

\section{References}

Amato, P. R., \& Booth, A. (1995). Changes in gender role attitudes and perceived marital quality. American Sociological Review, 60(1), 58-66. doi:10.2307/2096345

Amato, P. R., Booth, A., Johnson, D. R., \& Rogers, S. J. (2007). Alone together: How marriage in America is changing. Cambridge, MA: Harvard University Press.

Amato, P. R., Johnson, D. R., Booth, A., \& Rogers, S. J. (2003). Continuity and change in marital quality between 1980 and 2000. Journal of Marriage and the Family, 65(1), 1-22. doi:10.1111/j.1741-3737.2003.00001.x

Amato, P. R., Johnson, D. R., Booth, A., \& Rogers, S. J. (2007). Alone together: How marriage in America is changing. Cambridge, MA: Harvard University Press.

Armitage, J. S., \& Dugan, R. E. (2006). Marginalized experiences of Hispanic females in youth-based religious groups. Journal for the Scientific Study of Religion, 45(2), 217-231. doi:10.1111/j.1468-5906.2006.00302.x

Bagarozzi, D., \& Wodwarsky, J. (1977). A social exchange typology of conjugal relationships and conflict development. Journal of Marriage and the Family, 3(4), 53-60. doi:10.1111/j.1752-0606.1977.tb00485.x

Bahr, H. M., \& Chadwick, B. A. (1985). Religion and family in Middletown, USA. Journal of Marriage and the Family, 47, 407-414. doi: $10.2307 / 352140$

Bartkowski, J. P. (1999). One step forward, one step back: 'Progressive traditionalism' and the negotiation of domestic labor within Evangelical families. Gender Issues, 17, 37-61. doi:10.1007/s12147-998-0003-3

Batson, C. D., Schoenrade, P., \& Ventis, W. L. (1993). Religion and the individual: A social-psychological perspective. New York, NY: Oxford University Press.

Beere, C. A. (1990). Gender roles: A handbook of tests and measurements. New York, NY: Greenwood Press.

Booth, A., Johnson, D. R., Branaman, A., \& Sica, A. (1995). Belief and behavior: Does religion matter in today's marriage? Journal of Marriage and the Family, 57(3), 661-671. doi:10.2307/353921

Curtis, K. T., \& Ellison, C. G. (2002). Religious heterogamy and marital conflict: Findings from the National Survey of Families and Households. Journal of Family Issues, 23, 551-576. doi:10.1177/0192513X02023004005 
Dawkins, R. (2006). The god delusion. London, United Kingdom: Bantam Press.

Dudley, M. G., \& Kosinski, F. A. (1990). Religiosity and marital satisfaction: A research note. Review of Religious Research, 32(1), 78-86. doi:10.2307/3511329

Ellison, C. B., \& Bartkowski, J. P. (2002). Conservative Protestantism and the division of household labor among married couples. Journal of Family Issues, 23(8), 950-985. doi:10.1177/019251302237299

Ellison, C. G., Bartkowski, J. P., \& Anderson, K. L. (1999). Are there religious variations in domestic violence? Journal of Family Issues, 20, 87-113. doi:10.1177/019251399020001005

Fincham, F. D., Beach, S. R. H., Lambert, N., Stillman, T., \& Braithwaite, S. (2008). Spiritual behaviors and relationship satisfaction: A critical analysis of the role of prayer. Journal of Social and Clinical Psychology, 27(4), 362-388. doi:10.1521/jscp.2008.27.4.362

Gerson, K. (1993). No man's land: Men's changing commitments to family and work. New York, NY: Basic Books.

Hansen, G. L. (1987). The effect of religiosity on factors predicting marital adjustment. Social Psychology Quarterly, 50, 264-269. doi:10.2307/2786827

Heyman, R. E., Sayers, S. L., \& Bellack, A. S. (1994). Global marital satisfaction versus marital adjustment: An empirical comparison of three measures. Journal of Family Psychology, 8, 432-446. doi:10.1037/0893-3200.8.4.432

Hendrick, S. S., Dicke, A., \& Hendrick, C. (1998). The relationship assessment scale. Journal of Social and Personal Relationships, 15(1), 137-142. doi:10.1177/0265407598151009

Hochschild, A., \& Machung, A. (1989). The second shift: Working parents and the revolution at home. New York, NY: Viking.

Hoffmann, J., \& Miller, A. S. (1997). Social and political attitudes among religious groups: Convergence and divergence over time. Journal for the Scientific Study of Religion, 36(1), 52-70. doi:10.2307/1387882

Huntington, R. L., Fronk, C., \& Chadwick, B. A. (2001). Family roles of contemporary Palestinian women. Journal of Comparative Family Studies, 32(1), 1-19.

Johnson, M. P. (1999). The tripartite nature of marital commitment: Personal, moral, and structural reasons to stay married. Journal of Marriage and the Family, 61(1), 160-177. doi:10.2307/353891

Knudson-Martin, C., \& Mahoney, A. R. (2009). Introduction to the special section: Gendered power in cultural contexts: Capturing the lived experience of couples. Family Process, 48(1), 5-8. doi:10.1111/j.1545-5300.2009.01263.x

Kunz, P. R., \& Albrecht, S. L. (1977). Religion, marital happiness, and divorce. International Journal of Sociology of the Family, 7, 227-232.

Lehrer, E. L. (1995). The effects of religion on the labor supply of married women. Social Science Research, 24(3), 281-301. doi:10.1006/ssre.1995.1011

Merriam-Webster's Collegiate Dictionary. (1993). Springfield, MA: Merriam-Webster.

McMillen, E. K., Helm, H. W., Jr., \& McBride, D. C. (2011). Religious orientation and sexual attitudes and behaviors. Journal of Research on Christian Education, 20, 195-206. doi:10.1080/10656219.2011.590755 
Norton, R. (1983). Measuring marital quality: A critical look at the dependent variable. Journal of Marriage and the Family, 45, 141-151. doi:10.2307/351302

Orathinkal, J., \& Vansteenwegen, A. (2006). Religiosity and marital satisfaction. Contemporary Family Therapy, 28(4), 497-504. doi:10.1007/s10591-006-9020-0

Rabin, C., \& Shapira-Berman, O. (1997). Egalitarianism and marital happiness: Israeli wives and husbands on a collision course? The American Journal of Family Therapy, 25(4), 319-330. doi:10.1080/01926189708251076

Read, J. G. (2003). The sources of gender role attitudes among Christian and Muslim Arab- American women. Sociology of Religion, 64(2), 207-222. doi:10.2307/3712371

Rose, S. D. (2001). Christian fundamentalism: Patriarchy, sexuality, and human rights. In C. Howland (Ed.), Religious fundamentalisms and the human rights of women (pp. 9-20). New York, NY: Palgrave.

Rudman, L. A., \& Phelan, J. E. (2007). The interpersonal power of feminism: Is feminism good for romantic relationships? Sex Roles, 57(11-12), 787-799. doi:10.1007/s11199-007-9319-9

Sherkat, D. E. (2000). "That they be keepers of the home": The effect of conservative religion on early and late transitions into housewifery. Review of Religious Research, 41(3), 344-358. doi:10.2307/3512034

Spain, D., \& Bianchi, S. (1996). Balancing act: Motherhood, marriage, and employment among American women. New York, NY: Russell Sage.

Spence, J. T., \& Helmreich, R. L. (1972). The attitudes towards women scale: An objective instrument to measure attitudes toward the rights and roles of women in contemporary society. JSAS Catalog of Selected Documents in Psychology, 2(66) PG\#

Sullivan, K. T. (2001). Understanding the relationship between religiosity and marriage: An investigation of the immediate and longitudinal effects of religiosity on newlywed couples. Journal of Family Psychology, 15(4), 610-626.

doi:10.1037/0893-3200.15.4.610

Sussman, L. M., \& Alexander, C. M. (1999). How religiosity and ethnicity affect marital satisfaction for Jewish-Christian couples. Journal of Mental Health Counseling, 21(2), 173-185.

Thornton, A., \& Young-DeMarco, L. (2001). Four decades of trends in attitudes toward family issues in the United States: The 1960s through the 1990s. Journal of Marriage and the Family, 63, 1009-1037. doi:10.1111/j.1741-3737.2001.01009.x

Wallin, P. (1957). Religiosity, sexual gratification, and marital satisfaction. American Sociological Review, 22, $300-305$. doi: $10.2307 / 2088470$

Wilson, J., \& Musick, M. (1996). Religion and marital dependence. Journal for the Scientific Study of Religion, 35, 30-40. doi: $10.2307 / 1386393$

Zehrung, D. L. (1998). Causal attribution as a mediator between religiosity and marital satisfaction [Abstract]. Dissertation Abstracts International. B, The Sciences and Engineering, 59(3), 1388. 